\title{
THE STEAM ENGINE INDICATOR AS A DETECTOR OF LOST MOTION.
}

\author{
By Robert Grimshaw, M. E.
}

[Rent by tithe at the Stated Meeting of the Fraklin Institute, September 19, 1883.]

The improved steam engine indicators of the present day, while the legitimate suceessors of the original and long secret invention of James Watt, in the matter of merely showing the performances in the cylinder and valve-chest, and measuring horse-power, are gradually getting a wider applieation; and it is to one of their new applications, recently discovered, and not, to my knowledge, heretofore made public, that I desire to call your attention for a few moments.

A very intelligent engineer, Mr. Gilman W. Brown, of Boston, had put in his hands for remedy a most pronounced case of pounding in a high-ipeced engine. This machine thumped at high speeds and at slow speeds; at high pressures and at low pressures; at early and late cutolls, and under apparently all imaginable conditions of lead and compression. Wherever it was attempted to locate the thump, it appeared somewhere else; or at least was not where suspected.

There evidently was only one way to find out where that thump was:- to make it record itself-something which had never before been done, but which was now to be effected.

If the time, and the position in the stroke, at which the thump came in, could in some way be graphically recorded, the problem would be a long way towards solution.

Now, if an indicator can pick out the existence, and locate the time, of lost motion in a valve, why not in that of a crank-pin, or a crosshead pin, or a main bearing?

It is evident that whatever trace the tell-tale instrument should make of lost motion, outside of the valves, should not interfere with its record of the valve functions; and the natural deduction was that there must be another trace, neccssitating another marking-point, in no) wise connected with the indicator-piston, nor influenced by the steam-pressure.

To effect this, there was added to a "Crosby-Brown" indicator a second multiplying-lever, having a vertical motion only, and bearing a pencil making a trace underneath, and parallel, to the atmospherio and vacuum lines of the usual "diagram." This lever was pivoted to 
a little standard on the connecting-piece of the instrument, and the pencil position was adjustable in height by a spring and screw, the latter formed on a light rod passing through the connecting-piece. Vertical motion of this rod caused the pencil to vibrate vertically. If the rod was kept at a constant height, the pencil would trace a horizontal line partly around the paper cylinder; but any pull on the rod would make a jog in the tracing.

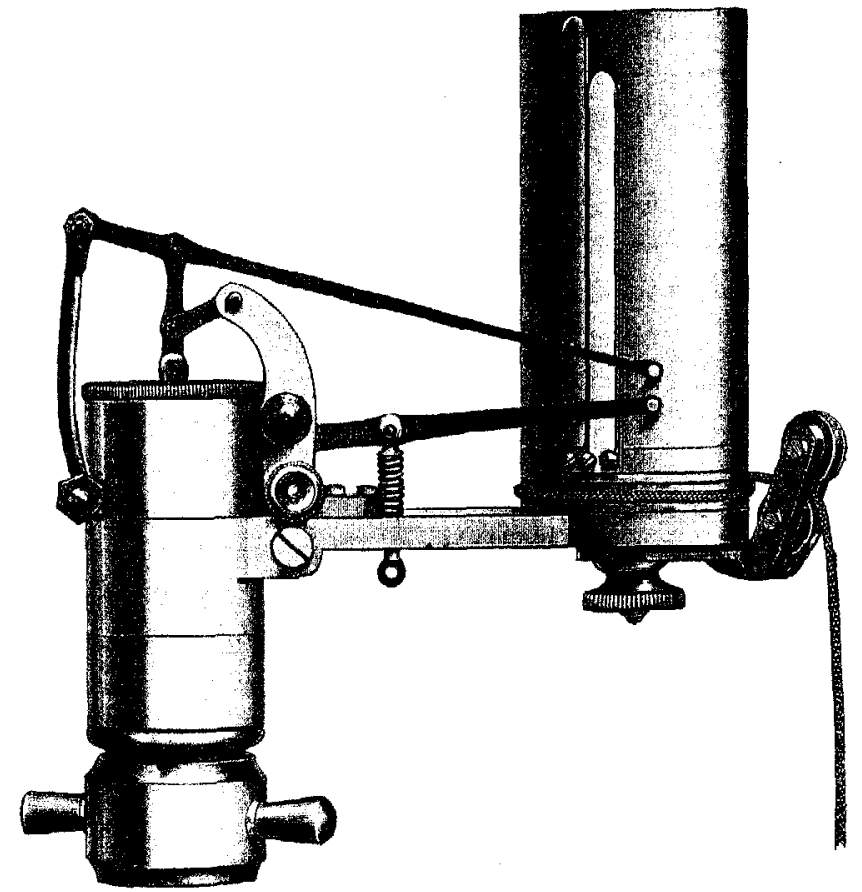

The main bearing being slacked up, a rertieal motal lever was pivoted to the bed-plate, so as to bear against the far side of the mainshaft (assumed to be truly cylindrical, and tested for this purpose. beforehand). The upper end of this lever was connected by a wire, or inelastic cord, passing around a guide-pulley, to the lower end of the vertical rod on the lost-motion lever of the indiuator, and all slack taken up, and held out by the spring on the vertical rod.

It is evident that if the main shaft las any horizontal movemen, it will cause horizontal vibration of the free end of the lever bearing against it, and thus tighten or slacken the cord and produce a vertical movement of the lost motion lever on the indicator. This 
will cause a jog, either below or above, in the supplementary horizontal line representing the crosshead path, and will indicate, beyond all question, where the lost motion commences, how long it lasts, in which direction it is from the normal, and when and where it stops.

By the aid of this rig, its inventor effectually cured the hitherto ineorrigible engine.

New York, September 8, 1883.

\section{THE WATER SUPPLY OF CITIES IN ANCIENT TIMES. By Watiter Atree, C. E.}

It would seem to be particularly interesting at the present time to give some account from ancient authors of the manner in which the famons water supplies of Rome and other cities, celebrated in antiquity, were conducted.

Ever since men have increased in numbers, and have dwelled together for a more or less time in one locality, great attention has always been given to obtain a permanent and abundant supply of pure water.

Among pagan nations water was regarded with such reverence that it was customary to give names to fountains ande springs, and to place them under the protcction of the gods.

The ancient Fgyptian priests, in order to show that all things could subsist only by the virtue of this element, carried solemnly, with religious respect, into the temple where their god was supposed to reside, an ornamental rase filled with water, and there prostrating themselves on the earth, with their hands raised, gave thanks to the divine goodness for his admirable inventions.*

In ancient Rome was celebrated annually on the III Ides of October (October 13), the feast of the fountains, under the name of Fontanalia. During the half day which the celebration lasted, the fountains and wells were crowned with flowers, and wreaths were thrown into the springs of ruming water.

The Germans, even a long time after the introduction of Christianity, continued in certain districts to make pilgrimages to several fountains conseernted to pagan gods.

If history furnishes but few and scattered accounts of the art of 